\title{
RENDIMENTO DO PROCESSAMENTO DE LINHAGENS DE TILÁPIAS (Oreochromis niloticus) EM FUNÇÃO DO PESO CORPORAL
}

\author{
Process yield of tilapias (Oreochromis niloticus) strains in function of body weight
}

\author{
Vander Bruno dos Santos 1 , Rilke Tadeu Fonseca de Freitas 2 , Priscila Vieira Rosa Logato ${ }^{2}$, \\ Thiago Archangelo Freato ${ }^{1}$, Laura Helena Orfão ${ }^{3}$, Lucas Cavaliere Millioti ${ }^{3}$
}

\begin{abstract}
RESUMO
Com o objetivo de avaliar os rendimentos do processamento de linhagens de tilápias em função dos pesos de abate, um experimento foi conduzido no setor de piscicultura da Universidade Federal de Lavras, M.G. - Brasil. Foram utilizados 93 peixes da linhagem Chitralada e 78 da Supreme, pesando entre 150 e 790 g. Os peixes foram cultivados em dois tanques de alvenaria de $40 \mathrm{~m}^{2}$, sendo alimentados com ração comercial fornecida de acordo com a biomassa e a temperatura da água. A temperatura e o oxigênio da água foram tomados diariamente, no início do dia e no final da tarde, e o pH aferido semanalmente. Com o crescimento dos animais, amostras aleatórias foram tomadas. Nas amostragens, os peixes foram abatidos após terem passado por um jejum de 24 horas e insensibilização por choque térmico. Em seguida, foram pesados e dissecados. A análise de regressão indicou que em pesos mais elevados, a linhagem Chitralada apresenta maior porcentagem de cabeça e rendimento de pele. A linhagem Supreme apresentou maior peso de carcaça, filé e resíduos, sendo mais expressivos em pesos superiores a $500 \mathrm{~g}$ e menor valor à maturidade para a \% de vísceras. Conclui-se que as duas linhagens possuem crescimento das partes componentes proporcional ao aumento do peso corporal, e este aumento não altera o rendimento desses constituintes. A linhagem Supreme apresentou maiores rendimentos de carcaça e filé do que a Chitralada, sendo a mais indicada para a produção e comercialização de filés mais pesados.
\end{abstract}

Termos para indexação: Chitralada, Rendimento de filé, rendimento de carcaça, supreme, tailandesa.

\begin{abstract}
With the objective of evaluating the yield processing of tilapia strains in function of body weight, an experiment was carried out at the Fish Culture of the Animal Sciences Department, Federal University of Lavras, M.G. - Brazil. A total 93 fish of the Chitralada strain and 78 of the Supreme strain, weighting between 150 and $790 \mathrm{~g}$ were used. The fish were cultivated in two tanks of $40 \mathrm{~m}^{2}$, fed with commercial ration supplied according to the biomass and water temperature. The water temperature and oxygen were evaluated every day, at the early morning and at the late afternoon, and the $\mathrm{pH}$ checked weekly. During the fish growth, random samples were taken. After 24 hours of fasting, the fish were insensibilized (thermal shock), slaughtered (anoxia), weighted and dissected. The regression analysis showed that in higher weight, the Chitralada strain presented higher head percentage and skin yield. The Supreme strain presented higher carcass, fillet and residue weights, being more expressive in body weights superior to $500 \mathrm{~g}$ and smaller limiting value for the percentage of viscera. It was concluded that the two strains have growth of body parts proportional to the increase of the body weight, and this increase does not modify the parts yield. The Supreme strain showed more carcass and fillet yield than Chitralada, and is should be indicated for production and commercialization of heavier fillet.
\end{abstract}

Index terms: Carcass yield, chitralada, fillet yield, supreme, thai

(Recebido em 27 de abril de 2004 e aprovado em 4 de março de 2005)

\section{INTRODUÇÃo}

O avanço da tilapicultura no mundo inteiro está levando a uma intensificação dos cultivos, provocado principalmente pela diminuição da pesca marinha e maior procura pelo pescado devido às qualidades saudáveis de sua carne. Um dos sintomas dessa intensificação é a busca por linhagens de desempenho superior. Várias linhagens de tilápia nilótica (Oreochromis niloticus, Linnaeus, 1757) têm surgido no mundo, dentre estas a Tailandesa ou Chitralada e a Genomar Supreme, que vêm merecendo especial atenção devido a seu comportamento dócil e elevado potencial de produção.
A tilápia está amplamente distribuída pelo território brasileiro e é criada nos mais diversos sistemas de produção. A intensificação da produção desta espécie no Brasil e o estabelecimento pelo Ministério da Agricultura de um programa de desenvolvimento da cadeia produtiva, principalmente para combater a importação de pescado, têm demandado pesquisas por linhagens geneticamente melhoradas e adaptadas aos nossos ambientes.

Vários fatores devem ser considerados na escolha da linhagem de tilápia a ser cultivada, tais como: adaptabilidade e tolerância a diferentes ambientes; facilidade de reprodução em cativeiro; elevada taxa de

${ }^{1}$ Aluno do curso de Doutorado em Zootecnia - Universidade Federal de Lavras/UFLA - Cx. P. 3037 - 37.200-000 - Lavras, MG.

${ }^{2}$ Professor Adjunto do Departamento de Zootecnia - Universidade Federal de Lavras/UFLA - Cx. P. 3037 - 37.200-000 - Lavras, MG - rilke@ufla.br ${ }^{3}$ Aluno de Graduação em Zootecnia - Universidade Federal de Lavras/UFLA - Cx. P. 3037 - 37.200-000 - Lavras, MG. 
crescimento; característica da carcaça e de carne compatível com as exigências da indústria de processamento e do consumidor final. De acordo com Souza et al. (2002b), a aqüicultura ainda apresenta deficiências em relação à falta de padronização do produto para o consumidor, o que acarreta dificuldades quanto às características de sabor, presença ou não de espinhas, forma de preparo e valor nutricional. Entretanto, se o produto tiver boa apresentação (postas ou filé) e embalagem (com especificação do produto), torna-se mais fácil o trabalho de marketing e, conseqüentemente, a colocação do pescado no mercado.

Para a indústria, a qualidade da carcaça do pescado é fator imprescindível para definição dos processos de preparação do produto e dos tipos de cortes. O rendimento de filé, além da eficiência das máquinas filetadoras e/ou destreza manual do operário, depende de algumas características intrínsecas à matéria prima, como a forma anatômica do corpo, tamanho da cabeça e peso dos resíduos (vísceras, pele e nadadeiras) (CONTRERASGUZMÁN, 1994; EYO, 1993; RIBEIRO et al., 1998).

Gasparino et al. (2002) afirmaram que o rendimento de filé varia de acordo com a espécie, entre as espécies e dentro da mesma espécie, possivelmente devido à falta de um sistema padrão nas metodologias de pesquisa nesta área.

Várias pesquisas têm demonstrado influência do peso de abate sobre o rendimento de carcaça e de filé em tilápias do Nilo (CONTRERAS-GUZMÁN, 1994; FREITAS et al., 1979; MACEDO-VIEGAS et al., 1997; SOUZA et al., 1998). Gasparino et al. (2002) e Souza et al. (2000, 2002a) concluíram que tilápias com peso superior a $400 \mathrm{~g}$, são as mais indicadas para abate, pois os rendimentos obtidos para as partes comestíveis são superiores.

O estudo dos rendimentos do processamento de tilápia pode propiciar um maior interesse econômico pela espécie ou linhagens, bem como, servir como referência para outros possíveis estudos. Além disso, as informações geradas por este tipo de estudo poderão ser de extrema importância para determinação do peso ideal de abate, caracterização do produto final e para o estabelecimento de programas de melhoramento genético. Assim, objetivouse avaliar os rendimentos do processamento de tilápias de duas linhagens comerciais, Chitralada e Supreme, em diferentes pesos de abate.

\section{MATERIAL E MÉTODOS}

\section{Instalações, material biológico e manejo}

Este trabalho foi conduzido no setor de piscicultura da Universidade Federal de Lavras-MG. Foram abatidos e dissecados 171 peixes, de uma população monosexo masculina, com pesos variando de 150 a 790 g, sendo 93 tilápias da linhagem Chitralada e 78 da Supreme. As tilápias foram cultivadas em tanques de alvenaria de $40 \mathrm{~m}^{2}$ e alimentadas com ração comercial fornecida de acordo com a biomassa e a temperatura da água. Os parâmetros de qualidade da água, temperatura e oxigênio, foram monitorados diariamente no início do dia e no final da tarde, e o pH aferido semanalmente. Durante o crescimento dos animais, foram retiradas amostras aleatórias com 30 peixes, sendo descartados aqueles com peso inferior a $150 \mathrm{~g}$ e superior a $800 \mathrm{~g}$.

\section{Abate e dissecação}

Após jejum por 24 horas e insensibilização por choque térmico, os peixes amostrados foram abatidos (anóxia), pesados e dissecados.

Para a avaliação dos rendimentos do processamento, foram pesadas as seguintes partes componentes dos peixes, obtidas conforme o fluxograma ilustrado na Figura 1:

a) escamas e nadadeiras (PEN);

b) cabeça (PC), seccionada do corpo na altura da junção com a altura vertebral, incluindo as brânquias;

c) vísceras (PV), compreendendo todo conteúdo da cavidade celomática, inclusive as gônodas;

d) carcaça (PCAR), compreendendo o corpo, excluído da cabeça, das vísceras, das escamas e das nadadeiras, sendo a nadadeira caudal seccionada à altura do perímetro peduncular;

e) pele (PP);

f) filé (PFSP);

g) resíduo da filetação da carcaça $(\mathrm{PR})$.

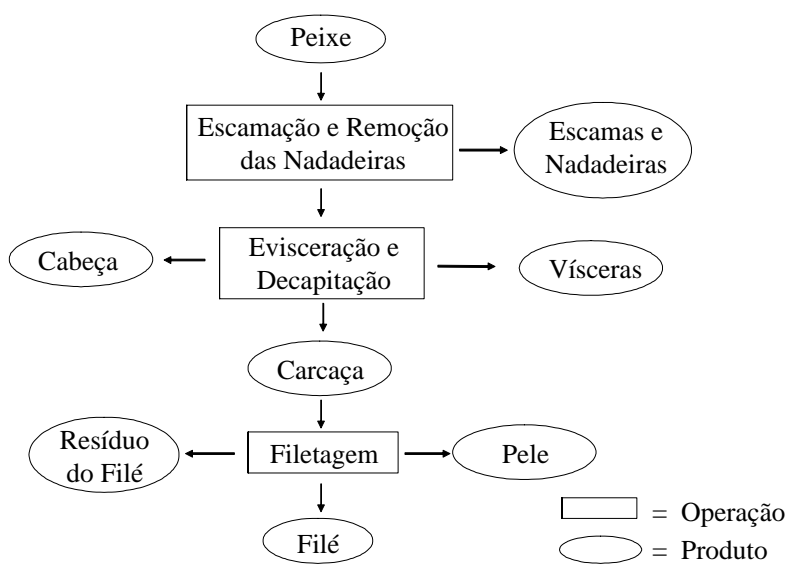

FIGURA 1 - Fluxograma do processamento manual da tilápia. 
Os seguintes rendimentos foram determinados como porcentagem do peso de abate: porcentagens de cabeça $(\% \mathrm{C})$, vísceras $(\% \mathrm{~V})$, escamas e nadadeiras $(\% \mathrm{EN})$ e resíduos da filetagem $(\% \mathrm{R})$; rendimentos de carcaça (RCAR), pele (RP) e filé sem pele (RFSP).

\section{Análise dos dados}

Os dados foram analisados através do modelo de regressão linear, utilizando-se variáveis "dummy" para comparação entre as linhagens, escrito da seguinte forma:

$$
\mathrm{y}_{\mathrm{i}}=\beta_{0}+\beta_{1} \mathrm{x}_{\mathrm{i}}+\alpha_{0} \mathrm{Z}+\alpha_{1} \mathrm{x}_{\mathrm{i}} \mathrm{Z}+\varepsilon_{\mathrm{i}}
$$

em que:

$\mathrm{y}_{\mathrm{i}}$ : observação da variável dependente no peso corporal $\mathrm{i}$, $\mathrm{i}=1,2, \ldots, \mathrm{n}$;

$\beta_{0}:$ coeficiente linear da reta;

$\beta_{1}$ : coeficiente angular da reta;

$\mathrm{x}_{\mathrm{i}}$ : peso corporal $\mathrm{i}$;

$\alpha_{0}$ : coeficiente associado a variável "dummy", estima a diferença entre as linhagens, no coeficiente linear da reta; $\alpha_{1}$ : coeficiente associado a variável "dummy", estima a diferença entre as linhagens, no coeficiente angular da reta;

Z: variável "dummy" que assume valor " 1 " para a linhagem Chitralada e "0" para a Supreme;

$\varepsilon_{i}$ : o erro associado a cada observação que por pressuposição é $\mathrm{N}\left(0, \sigma^{2}\right)$.

Nessa análise, a diferença entre os coeficientes (linear e angular) das equações de regressão, estimados para cada linhagem, foi testada pela estatística t, a um nível de significância igual a $5 \%$. Utilizou-se, para isso, o PROC REG do pacote computacional SAS Institute (1996) para Windows versão 6.12 .

Foram, também, testados modelos não lineares, exponencial e logarítmico, para aquelas variáveis que não apresentaram comportamento linear em função do peso corporal, optando-se por aquele de melhor ajuste. Os parâmetros das equações ajustadas para cada linhagem, nesse caso, foram comparados pelos seus intervalos de confiança com $95 \%$ de probabilidade. Estas análise foram realizadas utilizando-se os procedimentos PROC MODEL e PROC NLIN do pacote computacional SAS para Windows versão 6.12.

A hipótese de correlação serial dos resíduos não foi testada, pois cada peixe foi abatido, ou seja, analisado uma única vez. Não haveria explicação biológica se houvesse correlação entre eles.

\section{RESULTADOS E DISCUSSÕES}

Os pesos das diferentes partes componentes dos peixes (PEN, PC, PP, PCAR, PFSP e PR) aumentaram de forma linear $(\mathrm{P}=0,0001)$ com o aumento do peso corporal, indicando um crescimento proporcional dessas partes e, em geral, ocorreram de forma diferente para cada linhagem $(\mathrm{P}<0,01)$. Somente o peso das vísceras (PV) aumentou de forma não linear e semelhante nas duas linhagens.

A análise de regressão indicou que o peso das vísceras (PV) ajustou-se melhor a um modelo exponencial. $\mathrm{Na}$ Figura 2, ilustra-se esse comportamento, independentemente da linhagem, pois não houve diferença estatística nos parâmetros das curvas exponenciais.

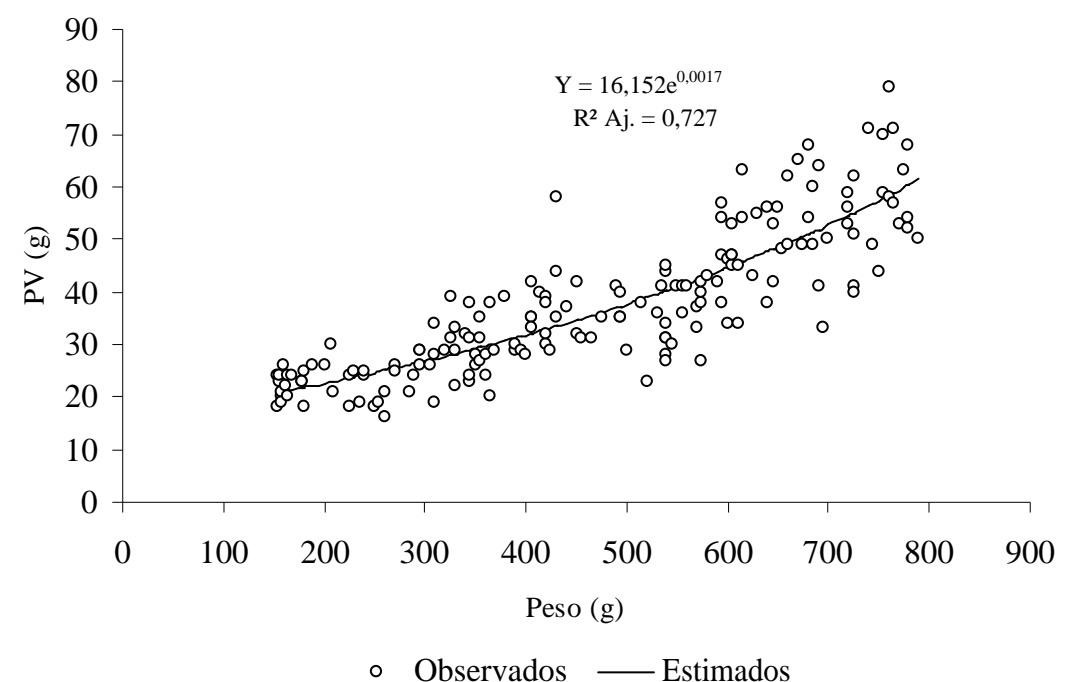

FIGURA 2 - Peso das vísceras (PV) em função do peso corporal das tilápias. 
As diferenças nas estimativas dos parâmetros das equações das retas ajustadas para as variáveis PEN, PC, PP, PCAR, PFSP e PR são apresentadas na Tabela 1.

O PEN obteve comportamento semelhante entre as linhagens, e as equações retas ajustadas podem ser consideradas iguais em seus parâmetros. Não havendo diferença, uma única curva para as duas linhagens pôde ser traçada (Figura 3).

Houve diferença significativa $(\mathrm{P}<0,01)$ nos parâmetros das equações das retas ajustadas para as variáveis PC, PP, PCAR, PFSP e PR entre as linhagens de tilápia. Pode-se observar pela Figura 4 que a linhagem Supreme apresentou maior peso da cabeça (PC) inicial e que, com o crescimento, ela foi significativamente superada pela Chitralada, pois esta teve um coeficiente angular $\left(b_{1}\right)$ da reta superior. Isso indica que em pesos mais elevados o peso da cabeça é superior na Chitralada.

Na Figura 5, ilustra-se o aumento linear no peso da carcaça (PCAR) com o aumento do peso de abate dos peixes, sendo mais expressivo na linhagem Supreme. Isso pode ser explicado pelo menor aumento no peso da cabeça encontrado nessa linhagem, quando comparada com a Chitralada (Figura 4).

TABELA 1 - Estimativa dos coeficientes linear $\left(b_{0}\right)$ e angular $\left(b_{1}\right)$ das equações ajustadas para os pesos de escamas e nadadeiras (PEN), cabeça (PC), pele (PP), fie sem pele (PFSP) e carcaça (PCAR) em função do peso corporal para as linhagens de tilápia.

\begin{tabular}{lccccc}
\hline \multirow{2}{*}{ Variáveis } & \multicolumn{2}{c}{$\mathbf{b}_{\mathbf{0}}$} & & $\mathbf{b}_{\mathbf{1}}$ & \multirow{2}{*}{$\mathbf{R}^{\mathbf{2}} \mathbf{A j}}$. \\
\cline { 2 - 5 } & Chitralada & Supreme & Chitralada & Supreme & 0,9296 \\
PEN & $0,6497 \mathrm{a}$ & $2,5385 \mathrm{a}$ & $0,1134 \mathrm{~A}$ & $0,1131 \mathrm{~A}$ & 0,9520 \\
PC & $-12,4382 \mathrm{~b}$ & $-1,5318 \mathrm{a}$ & $0,322 \mathrm{~A}$ & $0,2855 \mathrm{~B}$ & 0,8482 \\
PP & $-3,7116 \mathrm{~b}$ & $0,7958 \mathrm{a}$ & $0,0484 \mathrm{~A}$ & $0,0356 \mathrm{~B}$ & 0,9670 \\
PFSP & $-1,0009 \mathrm{a}$ & $-12,0437 \mathrm{~b}$ & $0,3156 \mathrm{~B}$ & $0,3573 \mathrm{~A}$ & 0,9271 \\
PR & $7,566 \mathrm{a}$ & $1,0947 \mathrm{~b}$ & $0,1346 \mathrm{~B}$ & $0,1540 \mathrm{~A}$ & 0,9847 \\
PCAR & $2,8535 \mathrm{a}$ & $-10,1533 \mathrm{~b}$ & $0,4989 \mathrm{~B}$ & $0,5469 \mathrm{~A}$ & \\
\hline
\end{tabular}

Valores seguidos de letras minúsculas para $\mathrm{b}_{0}$ e maiúsculas para $\mathrm{b}_{1}$ diferentes na linha, não são iguais pelo teste $\mathrm{t}(\mathrm{P}<$ 0,05), utilizando análise de regressão com variáveis "dummy”.

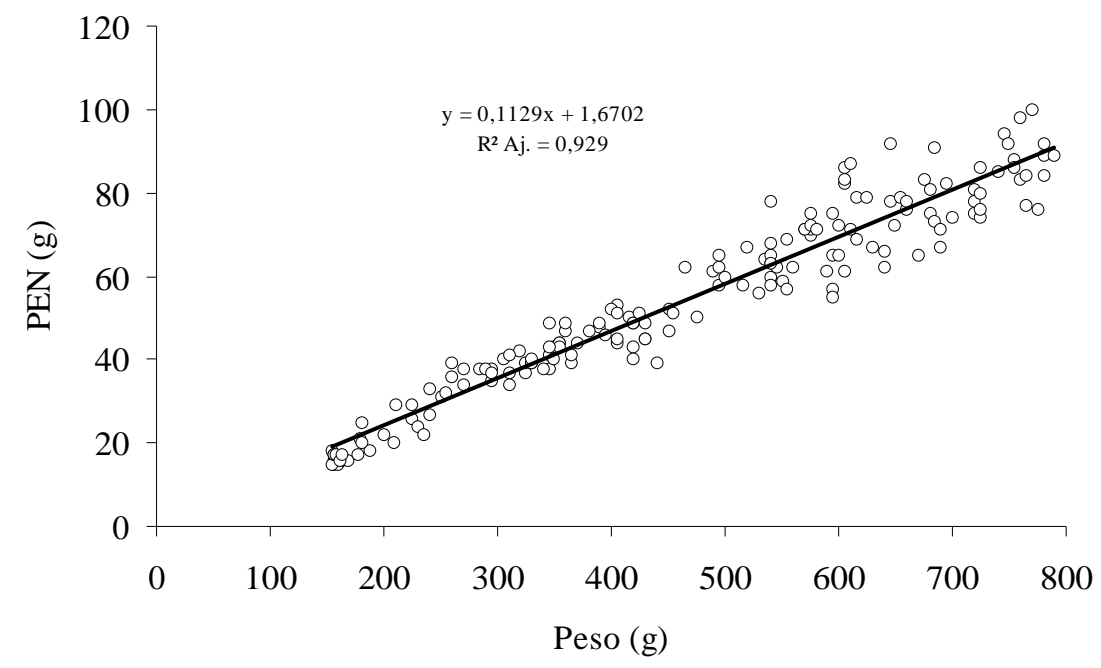

FIGURA 3 - Peso das escamas e nadadeiras (PEN) em função do peso corporal das tilápias. 


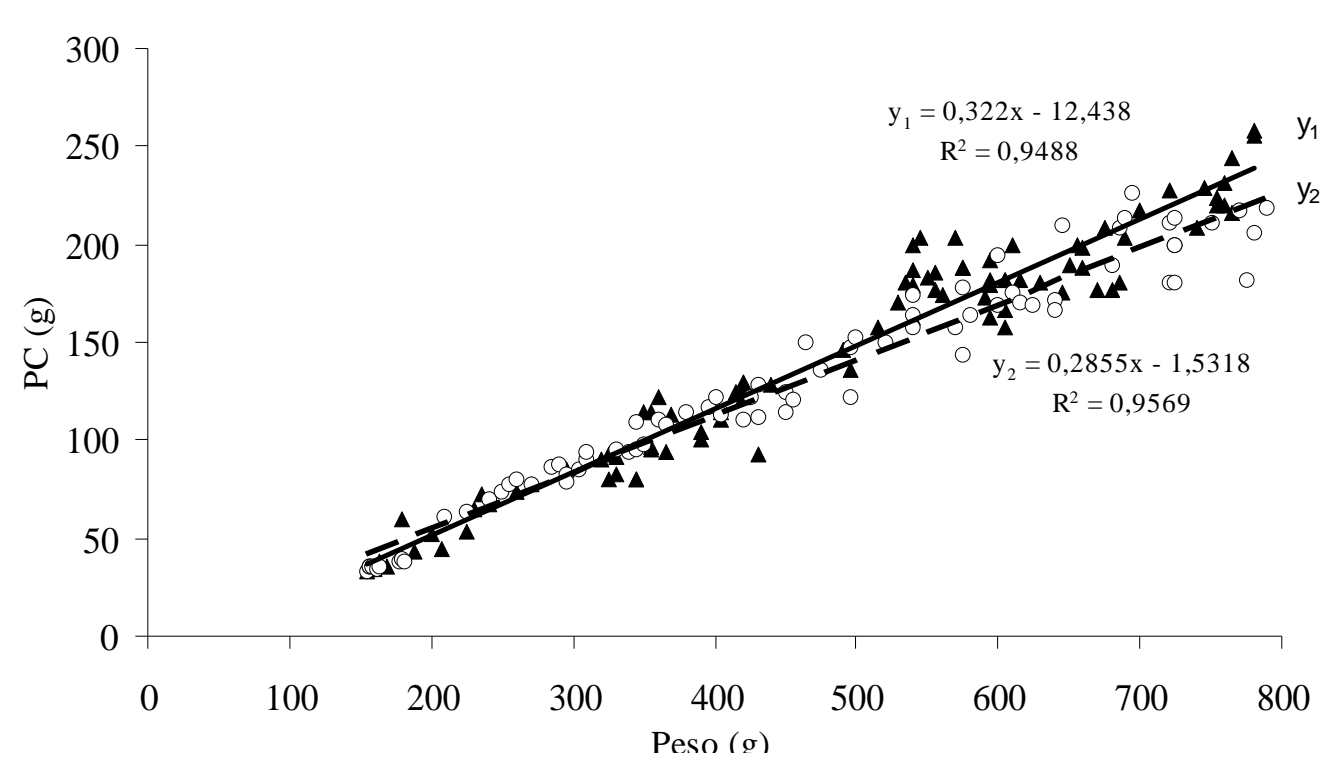

^ Chitralada

o Supreme

FIGURA 4 - Peso da cabeça (PC) em função do peso corporal das linhagens de tilápia: Chitralada $\left(\mathrm{y}_{1}\right)$ e Supreme $\left(\mathrm{y}_{2}\right)$.

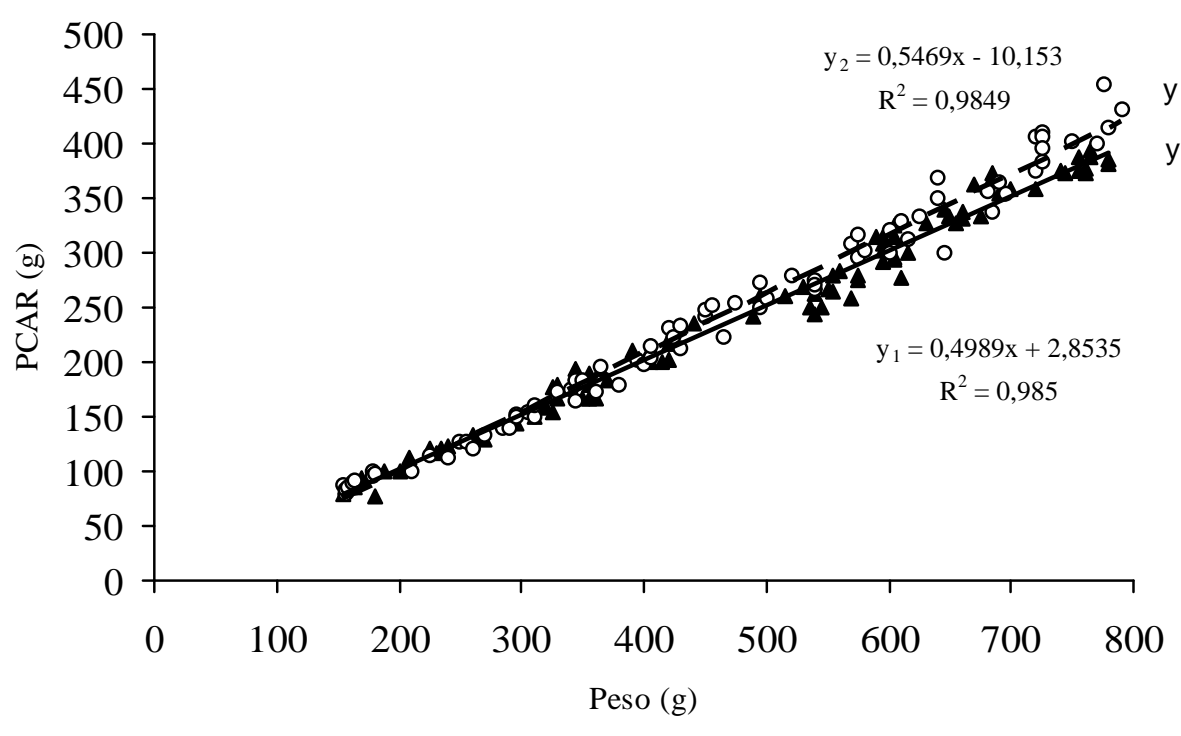

$\Delta$ Chitralada o Supreme

FIGURA 5 - Peso da carcaça (PCAR) em função do peso corporal das linhagens de tilápia: Chitralada $\left(\mathrm{y}_{1}\right)$ e Supreme $\left(\mathrm{y}_{2}\right)$.

Pode-se observar, pela Figura 6, que a linhagem Supreme apresentou maior peso da peso da pele (PP) inicial e que, com o aumento do peso de abate, ela foi significativamente superada pela Chitralada. Isso indica que em pesos mais elevados o rendimento de pele é superior na Chitralada.
Segundo Contreras-Guzmán (1994), a pele perfaz $7,5 \%$ do peso corporal dos peixes. Isso implica em um valor extremamente elevado e que pode ser destinada ao processamento, ou seja, curtimento. A resistência do couro à tração e alongamento e força de rasgamento progressivo são superiores no sentido transversalmente ao 
comprimento do corpo do peixe. A pele de tilápia pode ser transformada em couro para utilização na confecção de vestuário (SOUZA et al., 2002b).

Na Figura 7 pode-se comparar o aumento do peso do filé sem pele (PFSP) das duas linhagens, em função do aumento do peso corporal. Observa-se que em pesos inferiores a $350 \mathrm{~g}$, praticamente não existe diferença significativa entre elas. Entretanto, existe diferença em pesos superiores, e esta diferença tende a aumentar com o aumento do peso corporal.

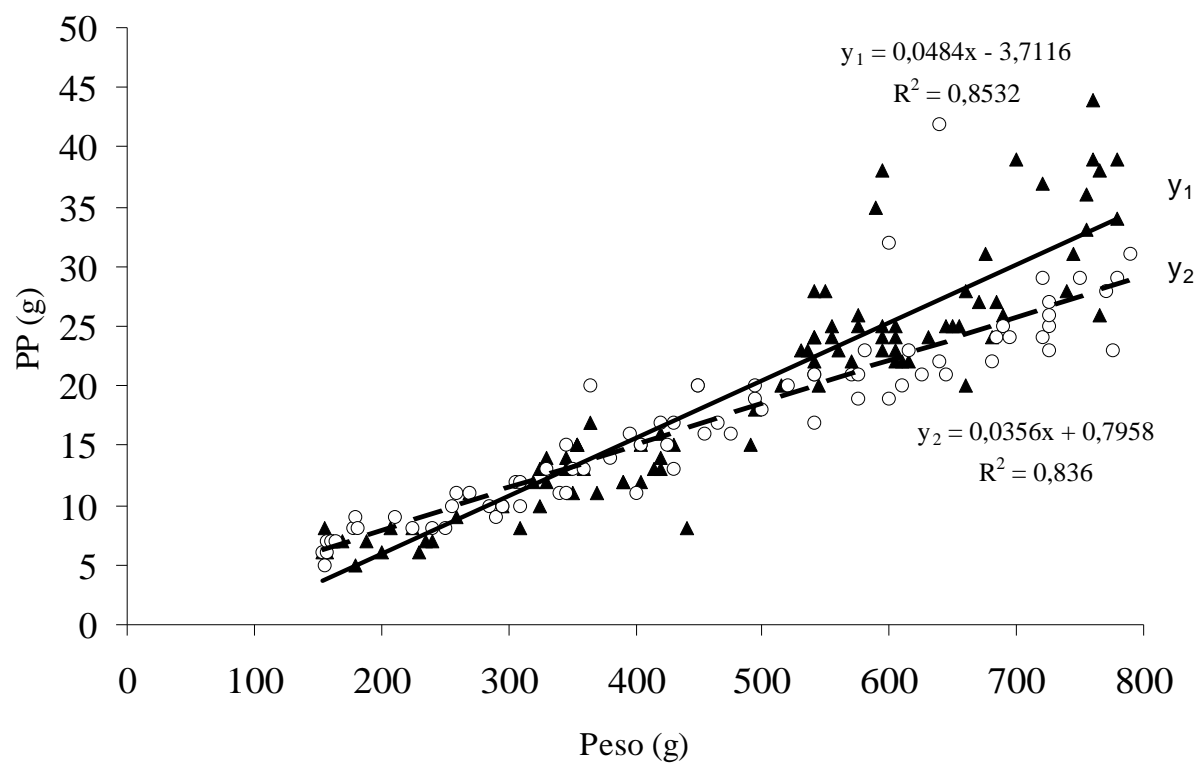

$\Delta$ Chitralada o Supreme

FIGURA 6 - Peso da pele (PP) em função do peso corporal das linhagens de tilápia: Chitralada $\left(\mathrm{y}_{1}\right)$ e Supreme $\left(\mathrm{y}_{2}\right)$.

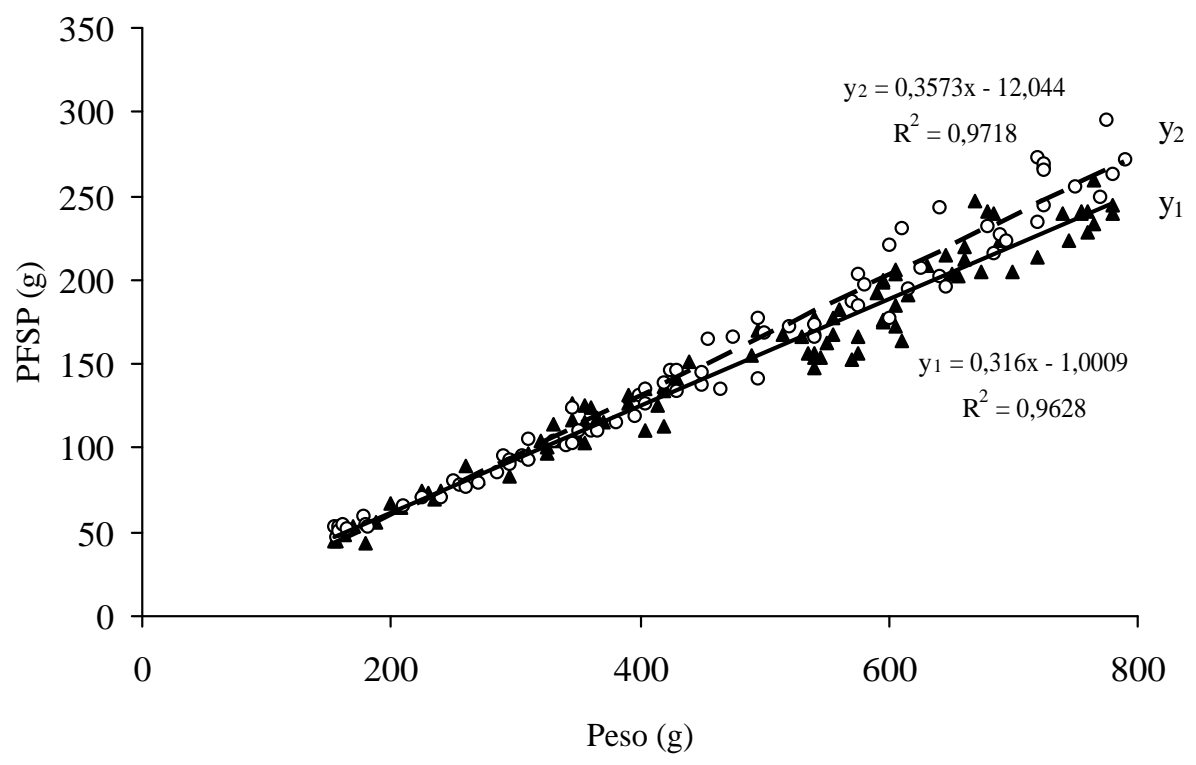

\Chitralada o Supreme

FIGURA 7 - Peso do filé sem pele (PFSP) em função do peso corporal das linhagens de tilápia: Chitralada $\left(\mathrm{y}_{1}\right)$ e Supreme $\left(\mathrm{y}_{2}\right)$. 
Isto já é um indicativo de que a linhagem Supreme possui maiores rendimentos de filé sem pele em peixes superiores a $350 \mathrm{~g}$. Em pesos mais elevados, como $750 \mathrm{~g}$, a diferença foi de 20,2 g no peso do filé sem pele, e isso equivale a uma diferença no rendimento de 7,9\%.

Pode-se observar que a diferença entre as linhagens no PCAR em peixes pesando $750 \mathrm{~g}$ é de $23 \mathrm{~g}$, valor menor que a diferença no PFSP. Um maior aumento nos pesos dos resíduos da filetagem na linhagem Supreme, pode ser a explicação para o ocorrido (Figura 8). Isso indica que a comercialização de carcaças pode garantir um maior retorno econômico para os criadores da linhagem Supreme, quando comparados com os criadores da linhagem Chitralada.

Pela Figura 8, ilustra-se o aumento do peso dos resíduos (PR) no processo de filetagem, com o crescimento e observa-se que esse aumento é maior na linhagem Supreme. Isso pode ser indicativo de que essa linhagem possui uma maior deposição óssea que a Chitralada, uma vez que esse resíduo da filetagem é composto principalmente pelas espinhas.
As variáveis RCAR, RFSP, RP, \%EN, \%C e \%R não foram significativamente influenciadas pelo aumento do peso. Esses resultados concordam com Gonçalves et al. (2001). Esses autores concluíram que os rendimentos de carcaça e filé não dependem do peso com que as tilápias do Nilo são abatidas. Somente a quantidade de filé na carcaça é relacionada com estes pesos.

A porcentagem de vísceras $(\% \mathrm{~V})$ foi influenciada pelo crescimento dos peixes e teve comportamento decrescente com o aumento do peso, nas duas linhagens. Os dados se ajustaram ao modelo de crescimento de Brody (1945) ou Monomolecular expresso da seguinte forma: $\mathrm{y}=$ $\mathrm{A}\left(1-\mathrm{Be}^{-\mathrm{kx}}\right)$, onde "y" é o valor da \% $\mathrm{V}$ e "x" o peso do peixe. Os parâmetros A e K possuem importantes interpretações biológicas e expressam respectivamente, o valor da \% $\mathrm{V}$ à maturidade do animal e a velocidade com que esse valor atinge a maturidade. Ao comparar o comportamento dessa variável entre as linhagens, podemos observar que houve diferença somente no parâmetro A, na qual linhagem Supreme obteve valor à maturidade $12,5 \%$ inferior a Chitralada. Isto está ilustrado na Figura 9.

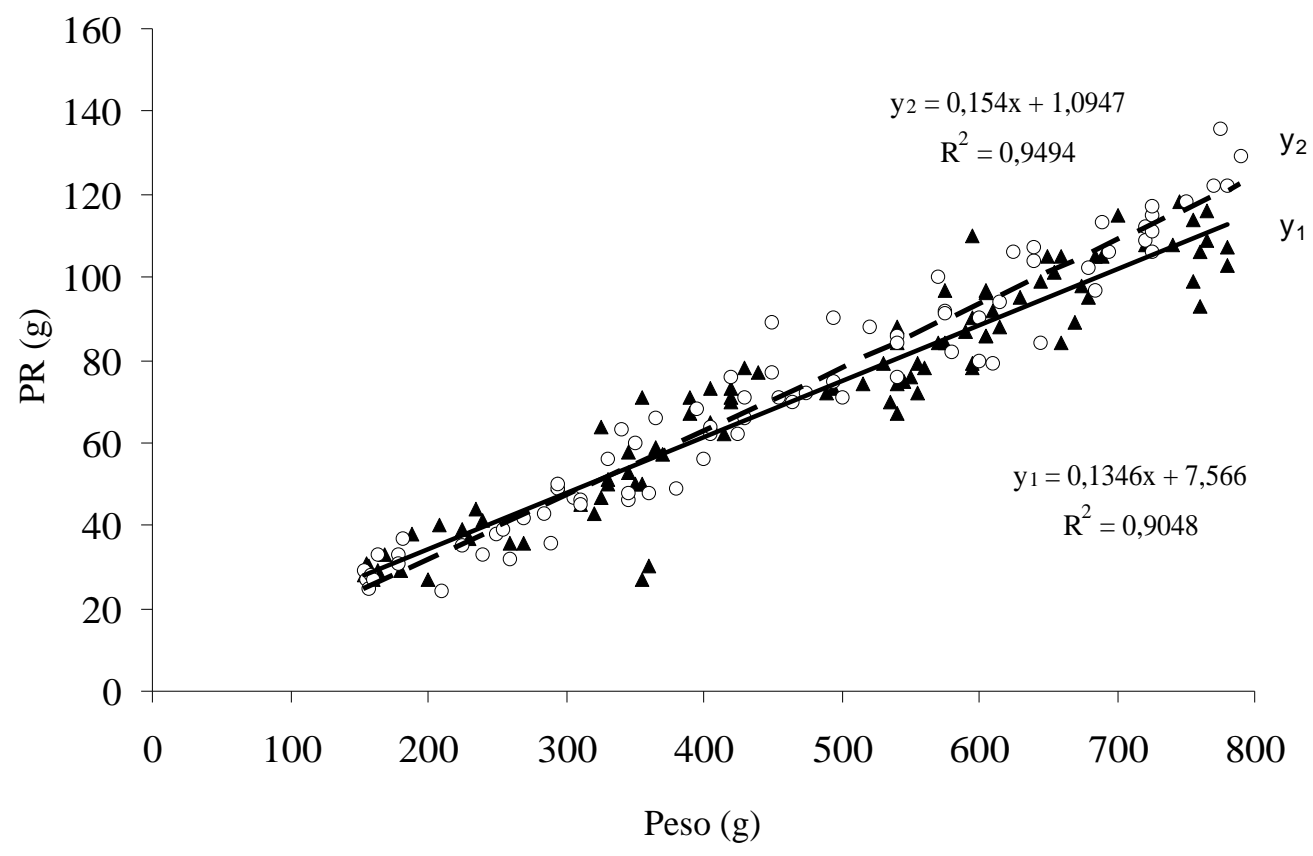

$\Delta$ Chitralada

○ Supreme

FIGURA 8 - Peso dos resíduos da filetagem (PR) em função do peso corporal das linhagens de tilápia: Chitralada $\left(\mathrm{y}_{1}\right)$ e Supreme $\left(y_{2}\right)$. 


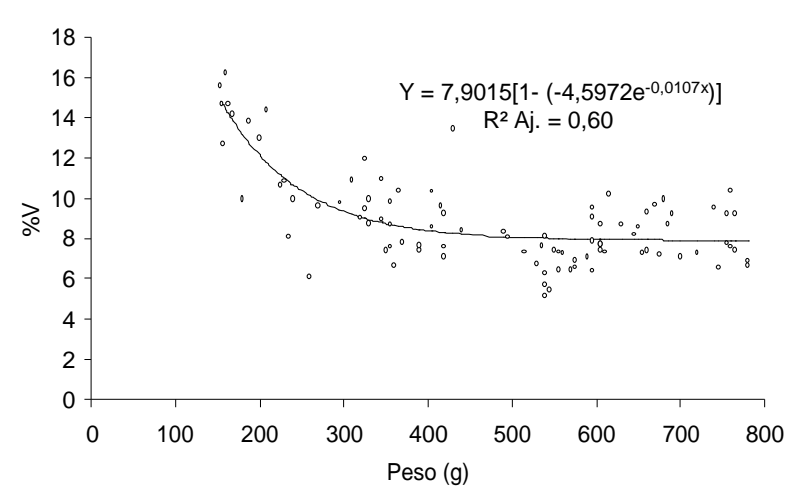

(a)

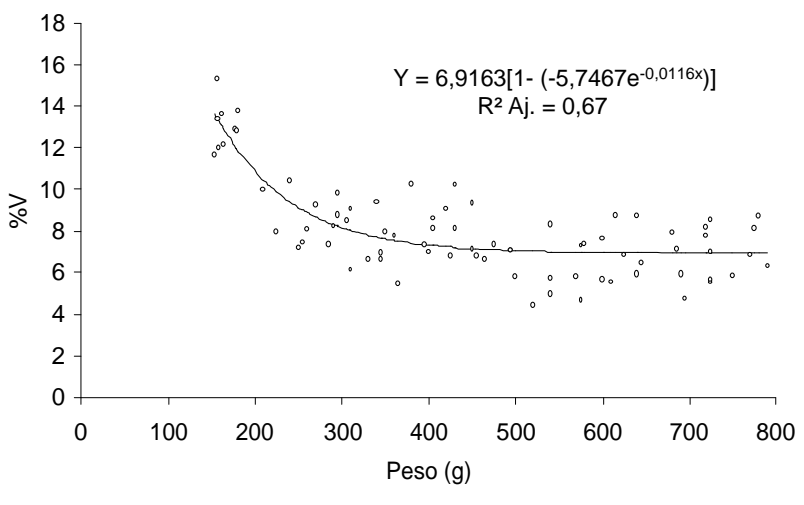

(b)

- Observados - Estimados

FIGURA 9 - Porcentagem de vísceras (\%V) em função do peso corporal das linhagens Chitralada (a) e Supreme (b).

Este resultado foi diferente do encontrado por VilasBoas (2001), segundo o qual, existe aumento significativo na porcentagem de vísceras e gordura celomática, em função do peso de abate de matrinchãs (Brycon cephalus), indicando uma preparação para a maturidade sexual.

\section{CONCLUSÕES}

Exceto para as vísceras, o crescimento das partes constituintes do corpo de tilápias das linhagens Chitralada e Supreme é proporcional ao aumento do peso corporal, e este aumento não altera o rendimento desses constituintes. Em pesos superiores a $350 \mathrm{~g}$, a linhagem Supreme apresenta maiores rendimentos de carcaça e filé do que a Chitralada, sendo a mais indicada para a produção e comercialização de filés mais pesados.

\section{AGRADECIMENTOS}

Os autores expressam seus agradecimentos às empresas Piscicultura Aquabel, pela doação dos alevinos, à Supra Alimentos e à Nutron, pela doação de parte da ração.

\section{REFERÊNCIAS BIBLIOGRÁFICAS}

BRODY, S. Bioenergetics and growth. New York: Reinhold, 1945. 1023 p.

CONTRERAS-GUZMÁN, E. S. Bioquímica de pescados e derivados. Jaboticabal: FUNEP, 1994. 409 p.

EYO, A. A. Carcass composition and filleting yield of ten fish species from Kainji Lake: proceedings of the FAO expert consultation on fish technology in Africa. FAO Fishers Report, Rome, n. 467, p. 173-175, 1993. Supplement.
FREITAS, J. V. F.; GURGEL, F. F. S.; MACHADO, Z. L. Estudos de alguns parâmetros biométricos e da composição química, inclusive sua variação sazonal da tilápia do Nilo, Sarotherodon niloticus (L) do açude público "Paulo Sarasate" (Reriutaba, Ceará, Brasil), durante os anos de 1978 e 1979. Boletim Técnico do Departamento Nacional de Obras Contra a Seca, Fortaleza, v. 37, n. 2, p. 135-151, jul./dez. 1979.

GASPARINO, E.; CAMPOS, A. T.; KLOSOVKI, E. S.; GUERREIRO, P. K.; FULBER, V. M.; LEAL, D. M.; SOUSA, I. de. Estudos de parâmetros corporais em tilápia do Nilo (Oreochromis niloticus). In: AQÜICULTURA BRASIL, 2002, Goiânia. Anais... Goiânia: ABRAq, 2002. p. 183.

GONÇALVES, T. M.; ALMEIDA, A. J. L.; OLIVEIRA, H. N. Avaliação de características de carcaças de tilápias do Nilo (Oreochromis niloticus). In: REUNIÃO ANUAL DA SOCIEDADE BRASILEIRA DE ZOOTECNIA, 38., 2001, Piracicaba. Anais... Piracicaba: SBZ, 2001.

MACEDO-VIEGAS, E. M.; SOUZA, M. L. R.; KRONKA, S. N. Estudo da carcaça de tilápia do Nilo (Oreochonis niloticus), em quatro categorias de peso. Revista Unimar, Maringá, v. 19, n. 3, p. 863-870, set. 1997.

RIBEIRO, L. P.; LIMA, L. C.; TURRA, E. M.; QUEIROZ, B. M.; RIBEIRO, T. G.; MIRANDA, M. O. T. Efeito do peso e do operador sobre o rendimento de filé em tilápia vermelha spp. In: AQÜICULTURA BRASIL, 1998, Recife. Anais... Recife: ABRAq, 1998. v. 2, p. 773-778. 
SAS INSTITUTE. User's guide: statistical analysis system institute. 5. ed. North Carolina: Cray, 1996. 956 p.

SOUZA, M. L. R.; CARACIOLO, M. S. B.; LÊMOS, J. B. de; COSTA, F. J. C. B.; ALENCAR, M. A. R. de. Avaliação do rendimento da carne da tilápia nilótica (Oreochromis niloticus). In: AQÜICULTURA BRASIL, 2002, Goiânia. Anais... Goiânia: ABRAq, 2002a. p. 231.

SOUZA, M. L. R.; CASTAGNOLLI, N.; KRONKA, S. N. Influência das densidades de estocagem e sistema de aeração sobre o peso e características de carcaça da tilápia do Nilo (Oreochromis niloticus). Acta Scientiarum, Maringá, v. 20, n. 3, p. 387-393, ago. 1998.

SOUZA, M. L. R.; DOURADO, D. M.; MACEDO-VIEGAS, E. M.; MACHADO, S. D.; FRREIRA, I. C.; SCAPINELLO,
C. Análise da pele de tilápia do Nilo. In: REUNIÃO ANUAL DA SOCIEDADE BRASILEIRA DE ZOOTECNIA, 2002, Recife. Anais... Recife: [s.n.], 2002b.

SOUZA, M. L. R.; MARENGONI, N. G.; PINTO, A. A.; CAÇADOR, W. C. Rendimento do processamento da tilápia do Nilo (Oreochromis niloticus): tipos de corte da cabeça em duas categorias de peso. Acta Scientiarum, Maringá, v. 22, n. 3, p. 701-706, ago. 2000 .

VILAS-BOAS, G. C. Morfometria, rendimento do processamento e composição química do filé de matrinchã Brycon cephalus (GUNTHER, 1869). 2001. 59 p. Dissertação (Mestrado em Zootecnia) - Universidade Federal de Lavras, Lavras, 2001. 